\title{
Simon Appleton
}

Mainstream economics has been accused of neglecting gender issues in general and the gender dimensions of 'structural adjustment' in particular. Yet economics provides useful tools and concepts for analysing these issues. Macroeconomic theory suggests a conceptual framework for tracing the effects of structural adjustment upon individuals. By identifying sectors which will be differentially affected, it implies that people will be differentially affected according to the sectors upon which they are dependent as producers and consumers. Within this approach, gender issues are relevant in so far as they lead to women being skewed into particular sectors and in so far as they impede women's intersectoral mobility. Analysis of household datasets is useful in giving empirical content to this structure, allowing the extent of gender differences in sectoral location and mobility in a specific country to be quantified and at least partially explained. At this level, economics is also helpful with microeconometric techniques providing powerful tools for such analysis.

The first part of this paper outlines the framework for analysing the gender dimensions of structural adjustment proposed by Collier [1989]. The second show how the issues arising from this approach can be analysed using standard econometric techniques and household survey datasets. Examples are provided by reporting on work in progress by the author and colleagues. The third part of the paper considers the advantages and limitations of such datasets for this work.

\section{The Role of Macroeconomic Theory}

There is no generally accepted definition of 'structural adjustment'. Here, it will be used loosely to refer to the experience of countries undergoing so-called 'structural adjustment programmes', usually devised with support from the IMF and/or the World Bank. Such programmes often cover a range of changes at the macroeconomic, sectoral and administrative level that may differ markedly from country to country. Consequently, the gender dimensions of such plans

This paper provides an overview of the methods and some of the results of work on the theme of the title by the Centre for the Study of African Economies. of which the author is a member. Consequently, it draws heavily on work by Paul Collier. John Hoddinott and Paul Horsnell. John Hoddinott provided useful comments on an earlier draft. The usual disclaimers apply can only be fully analysed by detailed study of particular cases. However, some general issues do arise when considering the macroeconomics behind many such programmes. Typically adopted in the wake of a negative external shock or the failure of alternative internal policies, structural adjustment often involves a degree of general 'belt-tightening' in the form of reductions of domestic absorption. This aspect of the policies is perhaps better defined as 'stabilisation' and may be unavoidable. How such an overall reduction in living standards is distributed will be influenced by the pattern of the accompanying changes in government spending and taxation. However, macroeconomic theory implies that even with a 'neutral' policy stance, structural adjustment will have systematically different effects on various sectors of the economy. It is well understood that the fall in domestic demand will tend to cause a 'real depreciation'. In other words, a fall in the relative price of 'non-tradables', those goods which are sheltered from international competition. Furthermore, adjustment to temporary external shocks may have differential effects on capital and consumer good industries. Moreover, there may be changes in trade policy, altering the price of protected tradables relative to those which are unprotected. Indeed, Collier (1989) defines structural adjustment as policies designed to und o the effects of inefficient stabilisation; typically taking the form of reversing an endogenous tightening of trade policy. Consequently, under this definition, structural adjustment - as opposed to stabilisation - will typically imply a rise in the prices of both non-tradables and unprotected tradables relative to protected tradables.

This theoretical framework implies that structural adjustment will have different implications for men and women if they tend to work in different sectors of the economy. For example, consider the effect of a real depreciation during adjustment. In some LDCs the food producing sector is largely non-traded and also uses predominantly female labour. Neoclassical theory suggests that in the short run, if labour is immobile, the returns to workers in a sector will vary proportionately with the price of the output of the sector. Hence, in the scenario given, structural adjustment would tend to redistribute income from women to men. Moreover, the relative price changes caused by adjustment call for a reallocation of 
resources to those sectors whose prices have appreciated. Consequently, in the example given, the onus on mobility fall onto women who would be expected to devote more of their time to the traded sectors. In the long run, with intersectoral mobility, there may also be different welfare effects by gender if male and female labour is not perfectly substitutable and can be regarded as separate factors of production. In particular, standard trade theory predicts that whether a factor gains or loses from a relative price change depends on how intensively it is used in a sector.

Structural adjustment may also involve gender issues if women are less mobile than men. Under such circumstances there is the danger that female labour is unable to relocate to those sectors which have benefited from the relative price changes brought on by structural adjustment. Such 'lock-in' effects will worsen existing gender inequalities in the distribution of income and impede the efficacy of structural adjustment as a whole. Gender skewness in economic activities and in mobility are distinct reasons for there to be a 'gender dimension to adjustment'. However, they are closely linked since such skewness may be caused by limited female mobility in the past. Discrimination by employers, lack of education, or child-rearing obligations may all inhibit female access to formal employment. Entry to certain high return informal sector activities - such as beverage crops in some parts of Africa - may often be denied to women due to problems in obtaining the credit required for the necessary investments. Empirical analysis of some of these issues is reported in the next section of the paper.

Although macroeconomic theory provides a useful conceptual framework, it does not allow one to make many substantive generalisations about the relative effects of structural adjustment on men and women. This is partly because the direction of the sectoral changes caused by various structural adjustment programmes may differ radically. ${ }^{2}$ Furthermore, the real world counterparts to open economy categories of non-traded goods, protected traded and so forth may well differ by country. Similarly, the extent to which there are gender differences in location across the appropriately defined sectors and in factor mobility may vary from country to country. The next section discusses how large scale household surveys are useful in providing data on these issues.

Finally, it should be noted that, if structural adjustment does have differential effects on men and women's incomes, this could have important consequences for household expenditures. Women's preferences over expenditures may differ from men's:

${ }^{2}$ For example, Appleton and Collier (1990) find very different relative price effects from structural adjustment in the Côte d'Ivoire and Ghana. in particular, it is sometimes claimed that women generally give a higher priority to children's goods than men do. Furthermore, it seems likely that changes in the income women provide will affect the extent to which household decisions reflect their preferences. For example, Sen [1985] proposes a bargaining model of the household which provides several reasons why a woman's ability to affect household decision making will increase with her income. Such theories have important implications for the effects of structural adjustment. Consider a "worst case' scenario of women being skewed into non-traded sectors and unable to relocate. Should structural adjustment require a real depreciation then women's share of income would fall, other things being equal. This would weaken women's bargaining power and consequently expenditure on children's goods including food - would fall by more than might be predicted merely from the aggregate cut in domestic absorption.

\section{The Role of Applied Microeconomic Analysis}

Analysis of large-scale national household survey data is an ideal method for investigating the distribution of male and female labour across broad macroeconomic sectors. The required information on gender and occupation - often combined with the time allocated to and income from a given occupation - is commonly available in household data sets such as the Living Standards and Measurement Surveys, LSMS, carried out by the World Bank. ${ }^{3}$ As with macroeconomic data, activities which are reported by function need to be re-classified according to the classifications suggested by open economy models. Appleton and Collier [1990] provide an example of this, combining the resulting information with a macroeconomic analysis of structural adjustment in Ghana and Côte d'Ivoire in the 1980s. Inferences are then made about the implications of adjustment in the two countries for the size distribution of income. A similar analysis focused on income distribution by gender would be feasible.

As well as providing data on gender skewness in activities, household surveys can also be used to investigate some of the causes of this skewness and of associated gender related barriers to factor mobility.

One important aspect of factor mobility is access to formal sector employment. This is analysed for urban Côte d'Ivoire by Appleton, Collier and Horsnell [1990] using the 1986 LSMS survey. The survey revealed that amongst those aged 16-64 who were not

\footnotetext{
${ }^{3}$ One limitation of existing I.SMS surveys, such ats those of the Côte d'Ivoire, for this purpose is the failure to record time use across different crops - some of which may be tradables and some not -produced by a household.
} 
in school, males in formal sector employment outnumbered females by four to one. ${ }^{4}$ If this reflects discrimination against women by employers, it may be a major obstacle to an efficient response to structural adjustment in the labour market. The possible existence of gender discrimination in pay was analysed by regressing wages upon observed characteristics of individuals to see if gender exerted a significant influence. Household survey data has an advantage over the work place surveys normally used for such studies. In particular, it provides information about non-participants in the labour market which can be used to control for some unobserved characteristics of wage-earners. For example, the relatively few women who do participate may be more productive than nonparticipating women (and men as a whole) in various ways that are not observed. If so, an absence of gender differentials in wages a mongst those in work may not indicate an absence of pay discrimination by gender. By modelling participation itself, standard econometric procedures following Heckman [1979] were applied to correct for any such sample selection bias. With this correction, no evidence of pay discrimination against women was found; indeed a dummy variable for male gender had a significant negative coefficient in the wage regression. ${ }^{5}$ Estimating more general models which allows the effect of other characteristics upon wages to vary by gender causes this apparent discrimination against males to disappear, with no marked pay discrimination by gender existing.

Further insight into the possible reasons behind the low proportion of women in employment in the Côte d'Ivoire was obtained by the probabilistic models of labour market participation. These hypothesised participation to be a function of the expected wages an individual would receive - as predicted by the wage equation previously reported - and various observed characteristics of the individual. Low levels of female education emerged as a major reason for their low levels of labour market participation. This was partly because educational credentials had a significant effect on the probability of participation independent of the expected wage. There was also an indirect effect via the expected wage. In particular, educational attainment was an important determinant of the wages an individual could expect to receive. Furthermore, whether an individual participated in the formal labour market depended heavily on these expected wages, with women's labour supply being particularly elastic. Interestingly, child rearing obligations did not appear to be a significant explanation of low rates of female participation. Both

\footnotetext{
${ }^{4}$ A person was defined as being in formal sector employment if their main work over the last year was in a non-family business and provided a monetary reward.

5 At the Workshop from which this paper arises. Diane Elson suggested that this may reflect occupational segmentation, with women less likely to be in the lower paid blue collar sectors.
}

marital status and the number of offspring were insignificant determinants of women's participation. Presumably kinship networks were sufficiently strong to provide child minders for those women who wished to work but had children. Nonetheless, there remained a 'pure' gender effect. That is to say, controlling for expected wages and observable characteristics, women are significantly less likely to participate. This could reflect the preferences either of women themselves or of potential employers, with the methods used providing no way of distinguishing these two explanations. However, the results of the model implied that if the lower participation of women is entirely due to their choosing to stay at home, their reservation wage - that is to say the lowest wage that would induce them to participate - must be nearly three times as high as that of men. This seems rather implausible, suggesting that employer discrimination may play an important role. Disaggregating the formal sector revealed that the pure gender effect on participation arose not in the public sector, but in the private unionised sector.

Lack of education as an explanation of low rates of female participation in urban employment has important long term implications. Improving girls' access to education may enhance an economy's responsiveness to structural adjustment and indeed to positive shocks. This argument is reinforced by the findings of Lockheed et al. [1980] that education enhances the adoption of efficient techniques in agriculture following price changes. Household survey data can be used to investigate why girls receive less education than boys and this formed the second part of Appleton, Collier and Horsnell's [1990] study of the Côte d'Ivoire. In the ten to 18 age range, girls were found to be nearly twice as likely as boys not to have any primary schooling. Moreover, probabilistic modelling of these schooling outcomes implied that, controlling for other factors, higher household income - whilst increasing the chances of a child being enrolled - would tend to leave the uneducated as an increasingly female group. This casts some doubt on the role of general economic development in reducing gender differentials in education and provides some support for the decision of the Ivorian authorities in subsequently making primary schooling compulsory. At a secondary school level, lower female enrolment - conditional upon having completed primary school - was found not to be directly attributable to low parental demand for girls' schooling as it had been at the primary level. Instead, it was largely due to girls' poorer performance in the primary leaving exam used to ration state secondary school places. This suggests that to enhance girls' access to secondary school, reforms should focus on performance in this exam. If primary schooling cannot be reformed to lessen gender differentials in attainment, positive discrimination in entry to state secondary school may be 
required. Interestingly, gender differentials in this exam - controlling for other characteristics - varied strongly with household consumption levels. The model implied that girls from poor households were markedly less likely than boys to pass the exam whilst there was little gender difference in the exam performance in children from households with mean levels of consumption.

Household survey data may also yield insights into constraints on factor mobility within agriculture. For example, tree crops such as tea are often important traded goods in African economies and hence increased adoption of such crops - at the expense of non-tradable food crops - may be part of a structural adjustment programme. However, using a 1982 survey of rural households in Central and Nyanza Provinces of Kenya, Bevan, Collier and Gunning [1990] found that female headed households were half as likely as male-headed households to adopt this crop following the 1975 boom in beverage prices. This effect was significant even after controlling for a household's labour endowments. Interestingly, the presence of female labour within a household significantly increased the probability of tea adoption whilst male labour had an insignificant effect. The authors interpret these results as indicating that, although cultivating tea is 'women's work', female-headed households face additional constraints in tea adoption to those facing male-headed households.

Besides being useful for examining the extent and causes of gender differences in activities and in mobility, household survey data can be used to investigate the argument that the pattern of household expenditures is sensitive to how much income women receive. Haddad and Hoddinott [1990] provide support for this argument by estimating expenditure functions with women's share of cash income as a determinant using the 1986 Ivorian LSMS data. Constructing this explanatory variable from the survey data was problematic. Employment income could be straightforwardly assigned by gender but the intrahousehold distribution of other income was not reported in the surveys. To try to overcome this, income from household businesses was assigned to the person judged 'best informed to discuss the business'. Income from sales of crops was assigned using anthropological data - such as that provided in Weekes-Vagliani [1985; 1990] - as to what are men's crops and women's crops in various regions of the Côte d'Ivoire. Once generated, the variable was then added to per capita expenditure, household size and household demographic composition as determinants in regressions for the expenditure shares of eight kinds of goods. The results showed that the gender distribution of income within a household was a significant determinant of the expenditure shares of six types of goods. Moreover, they suggested that 'a doubling of the proportion of household cash income accruing to women within the household would lead to almost a 5 per cent rise in the budget share of food expenditures and a fall of 20 and 11 per cent respectively in the budget shares of alcohol and cigarettes' (p.20). To the extent that food - as an important determinant of child anthropometric status - is a merit good (and alcohol and cigarettes are not!), these results suggest important consequences of the systematic redistribution of income by gender which structural adjustment may entail.

\section{Advantages and Limitations of Household Survey Datasets}

At the Workshop from which this paper arises, considerable scepticism was expressed by participants about the worth of large scale national household surveys of LDCs such as those from which the results of the previous section were obtained. However, it is worth noting several merits of this kind of data. Firstly, they are national and randomly drawn, holding out the promise of generating findings which are representative of a country as a whole. Secondly, they generate samples sufficiently large to allow for statistically significant findings to emerge. This allows the systematic testing both of descriptions of the data - such as gender differentials -- and of hypotheses about the processes generating the data. Large samples are particularly important when a number of variables which we would like to explain are discrete or 'censored'. For example, a woman either has secondary schooling or does not; she may work a positive number of hours in formal employment but may not work a negative number, etc. With such variables, the appropriate models are often maximum liklihood models whose desirable statistical properties require large samples. A third important advantage is that the surveys are integrated. That is to say, they inquire about a whole range of household activities: from formal employment to work on a household farm or enterprises; from consumption of marketed goods to access to public services. Hence, sophisticated estimates of household income are available as explanatory variables for analyses of gender differences in access to public services. Conversely, measurements of the use of public services - for example, education - can be used to explain income generation. The importance of this aspect of the surveys is sure to grow as more sophisticated techniques are developed to allow for the simultaneity of many household production and consumption decisions in LDCs. A related advantage is the fact that by focusing on the househoid and not, for example, the workplace - or the school - problems of sample selection are avoided. Indeed, differences in the characteristics of men and women in employment or in education may often be of secondary interest to the question of what characterises those without employment or education 
as compared to those with them. Finally, World Bank surveys such as the LSMS are to a large extent standardised across countries and overtime. Such comparability alows for inferences to be drawn about the effects of differences in policies across countries and overtime.

Against this list of advantages of large household surveys for analysing gender dimensions of structural adjustment there must be weighed a number of limitations. Conducting large scale surveys is costly and hence is often done in one or two interviews. There is thus little chance to check the accuracy of any reported information by observing a community at first hand over a long period. Moreover, by aiming to be so comprehensive, there is a danger that the surveys ask too many and too detailed questions for the answers to be considered reliable. This issue of reliability cannot be satisfactorily resolved by a researcher provided with only the survey results because it ultimately requires testing of the data from non-survey sources. However, one interesting general issue arises concerning possible biases - as opposed to random measurement error - of such data. In particular, the format of such surveys is to ask one household member to answer on behalf of the rest. ${ }^{6}$ This is obviously far from ideal when analysing intrahousehold issues such as the distribution of income or expenditure by gender. There may be an incentive for people to hide the extent of their earnings from their spouses, with the consequence that male household heads underestimate the earnings of their wives. Separate interviews would overcome this problem but again would be costly when conducted on a large scale. This perhaps an instance of a nother general limitation of surveys such as the LSMS: that in trying to be so comprehensive, they often fail to go in to the depth that research on a particular question requires.

A final drawback of the surveys is their one-shot nature. Structural adjustment is essentially a dynamic process requiring changes of behaviour by agents in response to changes in policy instruments. Observing a cross section of households at any period of time is necessarily limiting in what it can tell us about such a process. Hopefully the previous section has given examples of valuable insights that can be provided even by one shot surveys, but there is considerable potential for improvements when a time series of such surveys becomes available. Behaviour can be modelled as a response to changes in prices and government provision of goods and services. Moreover, repeated observations of the same households overtime offer yet further opportunities: transient changes in income and circumstances can be more easily isolated from underlying permanent states; potentially important unobserved 'fixed effects' of

\footnotetext{
6 The Ivorian LSMS selects different respondents for different parts of the survey according to who is claimed to know most ahout the relevant subject.
}

unobservable characteristics of the household can be controlled for; and the household itself - its formation and dissolution - can be studied.

\section{Conclusion}

Although the effects of a structural adjustment package will to some extent depend on its detailed measures, macroeconomic theory implies that there will be important sectoral changes. This provides a useful conceptual framework for examining the gender dimensions of adjustment. Additional constraints upon women as economic agents which skew women into particular sectors and limit their mobility will have consequences for both efficiency and distribution: impeding structural adjustment itself and causing it to change the gender composition of income, with possible effects on the pattern of household expenditures. However, specific predictions must be made on a case by case basis. This is because countries may differ both in the content of their structural adjustment packages and in their economic structures. Information on the latter can be provided by large scale national household surveys. Such data can also be used to investigate the additional constraints on women leading to any observed gender differences in economic activities and mobility. Work on Ivorian data has provided useful insights into gender differences in access to labour markets and about the relation of the gender composition of income to household expenditure patterns. When panels of such surveys become available, there will be opportunities for extending these partial insights to provide a more comprehensive analysis of the gender dimensions of adjustment.

\section{References}

Appleton, S. and P. Collier, 1990. 'Agriculture and the Macroeconomy: Consequences of Negative External Shocks in Ghana and the Côte d'Ivoire: 1979-87' mimeo, Centre for the Study of African Economies, Oxford University

Appleton, S., P. Collier and P. Horsnell, 1990, 'Gender, Education and Employment in Côte d'Ivoire', SDA Working Paper No. 8, The World Bank, Washington DC

Collier, P., 1989, 'The Impact of Adjustment on Women', mimeo, Centre for the Study of African Economies, Oxford University

Haddad, L. and J. Hoddinott, 1990, 'Household Expenditure and the Intrahousehold Distribution of Income: Evidence from the Côte d'Ivoire' mimeo, Centre for the Study of African Economies, Oxford University

Heckman, J., 1979, 'Sample Selection Bias as a Specification Error' Econometrica 
Lockheed, M., D. Jamison and L. Lau, 1980, 'Farmer Education and Farm Efficiency: A Survey' Economic Development and Cultural Change

Sen, A., 1985, 'Women, Technology and Sexual Divisions', Trade and Development
Weekes-Vagliani, W., 1985. 'Actors and Institutions in the Food Chain: the Case of the lvory Coast' Development Centre Papers, OECD, Paris

-1990. 'Analyse des Variables Socioculturelles el de l'Adjustment en Côte d'lvoire', Documents Techniques no 9. Development Centre Papers, OECD, Paris 